\title{
Correction: Intramyocardial block in patients with atrioventricular block
}

Li G, Saguner AM, Akdis D, et al. Intramyocardial block in patients with atrioventricular block. J Investig Med 2018;66:912-15. doi:10.1136/jim-2017-000682.

The legend to figure 4 should read as follows:

Recording of an endocardial signal in a patient who had an abnormal QTU and a spontaneous extrasystole occurring at the end of the T wave, a precursor of TdP. The endocardd tracing is a composite tracing obtained from 2 distal electrodes (ventricular) in parallel with 2 proximal (atrial) electrodes of a decapolar (Electrodyne, USA) catheter with electrodes $1 \mathrm{~cm}$ apart. The atrial as well as the ventricular deflections are clearly seen on the lower tracing and could be related to the surface ECG. The most important point of this figure is to show that during the extrasystole there is no rapid deflection on the endocardial signal suggesting an electrically silent zone under the electrode bipolar recording system. This original figure is from Guy Fontaine's work (Fontaine G. A new look at Torsades de Pointesa. Annals of the New York Academy of Sciences 1992;644:157-77).

(C) American Federation for Medical Research 2018. No commercial re-use. See rights and permissions. Published by BMJ.

J Investig Med ;66:1068. doi:10.1136/jim-2017-000682corr1

Check for updates 